\title{
Determinants Households: of Food insecurity: The Case of Boloso Bombe Woreda, Wolaita Zone, Southern Region, Ethiopia
}

\author{
Yisehak Ossa Jokka \\ College of Business and Economics, Wolaita Sodo University, Wolaita Sodo, Ethiopia
}

\begin{abstract}
Food insecurity refers to a situation that exists when people lack secure access to sufficient amounts of safe and nutritious food for normal growth and development and an active and healthy life. The general objective of the study was the general objective of the study was to identify the determinants of food insecurity among rural households in Boloso Bombe Woreda. Household levels and food insecurity studies at the national level fails to articulate household level availability and access to needed food. A multistage sampling technique employed to select 379 households. Both quantitative and qualitative data were collected from sampled households through questionnaire and interview. Both descriptive and econometric data analyses techniques were applied. From the econometrics result revealed that family size, dependency ratio, farm size, farm income, nonfarm income, livestock number, distance from the market and household production system were significantly affect the food insecurity status in the study area .It was observed that $82.4 \%$ of the sampled households of the Woreda were food insecured while $17.6 \%$ were found to be food secured households from the survey result. According to from descriptive result most of households food insecure were dependent age groups households, to minimize this problem there should be teaching and training adult and young age groups to escape from the food insecurity problems.
\end{abstract}

Keywords: Food security, Binary logistic regression.

DOI: $10.7176 / \mathrm{CER} / 11-7-02$

Publication date: August $31^{\text {st }} 2019$

\section{INTRODUCTION}

According to FAO (2012), about 870 million people are estimated to have been undernourished in the period 20102012. This figure represents $12.5 \%$ or one in eight people of the global population are in the problem of undernourishment. From these figure, the vast majority; 852 million, live in developing countries, where the prevalence of undernourishment is estimated latter at $14.9 \%$ of the population.

However, still today throughout the world food shortage and insufficiency or food insecurity is a number one global extreme challenging problem. The depth of the problem is deep rooted in the developing nations specially, East Asian and Sub Saharan African countries. After two years later in this the same reports in the world in 2014 there were 842 million people who do not have enough food to eat, and most of them are women and girls (CARE, 2014)

Almost all findings in the area of food security studies by FAO, 2016, WFP, 2016 and by FSIN, JanuaryFebruary 2017 states that food security and insecurity are terms used to describe whether or not people have access to sufficient quality and quantity of food. According to Tagel (2012), food security and insecurity are mostly affected by factors such as poverty, health, food production, political stability, infrastructure, access to markets, and natural hazards.

FAO (2010) states that over 40 per cent of the population in the Horn of Africa is undernourished and millions are food insecure. According to (FAO, 2010) subsistence farmers, pastoralists and agro-pastoralists whose livelihoods largely depend on agriculture and livestock rearing, are the main categories of food insecure people.

In Ethiopia food insecurity is highly prevalent in moisture deficit highland and in the lowland pastoral areas. Even in years of adequate rainfall and good harvest, the people, particularly in lowland pastoral and agro-pastoral areas, remain food insecure and in need of food assistance. This clearly reflects the deeply entrenched poverty and food insecurity situation in the country irrespective of adequate rainfall (Arega, 2013). Most famines and food crisis in Ethiopia have been geographically concentrated in two broad zones of the country. The first consist of the central and northern highlands, stretching from northern Shewa through Wello and Tigray, and the second is made up of the crescent of low-lying pastoral and agro-pastoral lands ranging from Wello in the north, through Hararghe and Bale to Sidamo and GamoGofa and South Omo in the south (Workneh, 2004).

The recent study on food security situation in Ethiopia stated that, food insecurity is an enduring, critical challenge in Ethiopia which is Africa's second populous country after Nigeria. The 2015 El Nino drought is one of the strongest droughts that have been recorded in Ethiopian history were more than 27 million people become food insecure and total of 18.1 million people required food assistance in 2016 and also as indicated by Africa Food Security and Hunger Multiple Indicator Scorecard Ethiopia ranked first in having the highest number of people in state of undernourishment which is 32.1 million people in 2015 (Abduselam, 2017).

The study area, Boloso Bombe Woreda in Wolaiata zone in SNNPR Regional State is not different from other parts of the country with respect to the situations of poverty and food insecurity. The area is food shortage, range 
land degradation, very limited or inexistence of infrastructure and social services, marginalization, environmental problems like recurrent drought and its related negative outcomes and generally poverty and food insecurity have become the picture of the area for the last several decades (BWOANRD, 2016).

\section{Objectives of the Study}

2.1 General Objectives

The general objective of the study was to identify the determinants of food insecurity among rural households in Boloso Bombe Woreda.

\subsection{Specific Objective}

1. To measure the rural households food insecurity status in Boloso Bombe Woreda

2. To compare socio-economic and demographic characteristics of both food secure and food insecure households in the study area.

3. To examine determinants of food insecurity among households in Boloso Bombe Woreda

\section{RESEARCH METHODOLOGY}

\subsection{Description of the Study Area}

Boloso Bombe, on the other hand, is a woreda in the zone with a total population of about $117,330(57,131$ male and 60,199 female). The 2007 census also shows the population constitutes about 14,039 and 3,620 male and female household head respectively. As far as the agro ecological back ground of the woreda is concerned, the area seems to be mainly 'kola' (75\%) followed by 'woyna dega'( $20 \%)$ and dega (5\%) with the altitude ranging from $1375 \mathrm{~m}$ to $2277 \mathrm{~m}$ above sea level. The total area of the woreda is about 21,859 ha out of which 13,592 ha $(62 \%)$ is cultivable land. About 1560 ha is grazing land, and the area of 3207 ha is covered by tree. The remaining 3500 ha land is found to be uncultivable. Agriculture especially crop production is the dominant form of economic activity where ginger production takes a lion share followed by cereals like maize, teff, etc. and root crops such as enset, sweet-potato and potato.

\subsection{Types and Sources of Data}

This study was conducted based on the procedures of mixed methods approach. This means, a mixture of data collection and analysis techniques used from both the quantitative and qualitative research methods. The mixed approach is preferred for this study since it enables to use different methods of data collection and analysis for addressing the problem effectively. Again, survey design is the kind of the research design used in the study. Specifically, cross-sectional survey design was employed for this study.

The study was conducted based on both primary and secondary data sources. Primary data was collected through questionnaire, interview, focus group discussion and field observation; while the secondary data will be collected from review of related literature, government office reports, NGOs, research papers, books, journals and other related documents.

\subsection{Sampling Techniques and Sample Size Determination}

An important element that are determining in setting sample size is nature of universe ( homogeneity and heterogeneity of the population), number of class proposed, nature of study, types of sampling technique, standard of accuracy, availability of finance, and other considerations ( Kothari, 2004).

After these entire criterion mentioned above, the next important decision that has to be taken while selecting a sampling technique is about the size of the sample.

Multi stage sampling methods were used in this study. First the Boloso Bombe woreda was selected purposively due to severity of food insecurity problems and proximity. Then, based on the agro ecology and farming system of the woreda, the 22 rural Kebeles was classified in to two strata, as 17 in low land(kola) and 5 mid dry land ( woyna dega) Kebeles. The total population in this five kebele was 7,160. Then after, proportionately from the two strata the five Kebeles were selected randomly.

Thus, Sample households were selected via simple random sampling following probability proportional to size (PPS) technique.

Finally, the number of sample households will be determined based on (Yamane, 1967) formula to determine the required sample size at $95 \%$ confidence level, and level of precision $=5 \%(0.05)$

Hence, the formula will be as below:

$$
\begin{aligned}
& \mathrm{n}=\frac{\mathrm{N}}{1+\mathrm{N}(\mathrm{e})^{2}} \\
& \mathrm{n}=\frac{7,160}{1+7,160(0.05)^{2}}=379 \mathrm{HHs}
\end{aligned}
$$

\subsubsection{Data Collection Instruments}

In this study, different instruments were used for gathering data about the determinants, status, socio economic 
and demographic characteristics of food insecurity. Thus, detailed description made about the instruments to use in this study.

\subsubsection{Questionnaire}

The household survey was conducted to supplement the other basic field methods for generating quantitative data determinants of food insecurity of households of the study area. The survey undertaken in four-selected sample Kebeles where a total of 379 questionnaires was distributed and collected the survey data. The question involves both open and close-ended questions.

The other instruments important to collect qualitative data supportive for the data collected by questionnaires are key informant interview (KII), field observation, and focus group discussion (FGD). KII was conducted at Zonal, and woreda level expertise and other responsible officials.

\subsection{Methods of Data Analysis}

The study was employed both descriptive and econometrics data analyses to achieve the objectives.

\subsubsection{Descriptive Statistics}

Descriptive statistics including percentages mean values, frequencies, used to describe food secure and food insecure households in the study area based on important socio-economic, institutional and demographic factors.

\subsubsection{Measuring Food Insecurity Status}

According to Meseret (2013) and Mohammed (2016), the households' food insecurity status measured by direct survey of income, expenditure, and consumption. However, in this study food or calorie acquisition/consumption per adult per day used to identify the food secure and insecure households. The person responsible for preparing meals asked how much food prepared for consumption from production, purchase, stock and/or gift/loan/wage over a period of seven days. In this study, a seven-day recall method used since such a measure gives more reliable information than the household expenditure method. According to Gulled (2006), these seven days recall period will be selected due to the fact that it is appropriate for exact recall of the food items served for the household within that week. If the time exceeds a week, for instance 14 days, the respondent may not recall properly what she served before two weeks.

The consumption food sources for the households will be of different types like own production, loan, and gifts as aid, and purchase and so on. Therefore, the consumption data collected on the basis of seven days recall method will be converted into kilocalorie using the food composition table adopted from (Ethiopian Health and Nutrition Research Institute [EHNRI], 2000). Then, in order to calculate the household's daily food consumption, seven will divide the total household's caloric food consumption for seven days. The household's daily caloric food consumption per adult equivalent calculated by dividing the household's daily food consumption by the family size after adjusting for adult equivalent using the conversion factor for age sex categories. Then the result will be compared with the minimum subsistence requirement per AE per day of 2,200 Kcal value is used as a cutoff point between food secure and insecure households in which case the household is said to be food insecure if it not meets this minimum and secure otherwise.

\subsubsection{Econometric Analysis}

To examine the determinants of food insecurity situation of the households a logit model is an important empirical tool in this study. Because, the dependent variable Y (household food insecurity status) is dichotomous variable; means taking a value 1 if the household is food insecure and 0 otherwise. For such a case where the dependent variable is a dichotomous, probability regression models is the most fitted to study the relationship between dependent and independent variables. In other words, it can be common when the response variable is qualitative; and the probability of the dependent variable given independent variable that was determined. Of which the most common qualitative regression model is logit model as stated in Gujarati (2004).

In general, in this study model, the dependent variable would takes a value of 1 if the household belongs to food insecure with the probability of Pi otherwise a value of 0 , i.e. food secure with the probability of 1-Pi

Therefore, the logistic distribution function for determining factors for food insecurity among the households can be specified in Gujarati (1995), as follows:

$\left.\mathrm{P}_{\mathrm{i}}=\mathrm{F}\left(\mathrm{Z}_{\mathrm{i}}\right)=\mathrm{F}\left(\beta_{0}+\sum \beta \mathrm{iXi}\right)=\frac{1}{1+\mathrm{e}^{-\left(\beta_{0}+\sum \beta \mathrm{iXi}\right)}}\right)$-------------- $(1)$

Where:

$\mathrm{P}_{\mathrm{i}}=$ is the probability that an individual is food insecure,

$\mathrm{X}_{\mathrm{i}}=$ represents vector of the $\mathrm{i}^{\mathrm{th}}$ explanatory variables,

$\beta_{0}=$ is a constant term a vector of coefficient to be estimated, $\mathrm{i}=1,2 \ldots \mathrm{m}$,

$\beta_{i}=$ is the slop of the equation in the model (parameters to be estimated)

$\mathrm{e}=$ is the base of the natural logarithm (2.718)

$\mathrm{Z}_{\mathrm{i}}=$ is a function of explanatory variables $\mathrm{X} i, i=1 \ldots \mathrm{m}$ which may be expressed as:-

$Z_{i}=\beta_{0}+\beta_{1} X_{1}+\beta_{2} X_{2}+\cdots+\beta_{m} X_{m}$

The above equation (1) can be written in the form of the odds ratio and logs of odds ratio to interpret the 
coefficients. Accordingly, the odds ratio of households will be food insecure $\left(P_{i}\right)$ to the probability of a household will be food secure $\left(1-P_{i}\right)$.

$$
\begin{array}{r}
\left(1-P_{i}\right)=\frac{1}{1+e^{Z i}} \\
{\left[\frac{P_{i}}{1-P_{i}}\right]=\left[\frac{1+e^{Z i}}{1+e^{-Z i}}\right]=e^{Z i}} \\
{\left[\frac{P_{i}}{1-P_{i}}\right]=\left[\frac{1+e^{Z i}}{1+e^{-Z i}}\right]=e^{\left(\beta_{0}+\sum \beta i X i\right)}}
\end{array}
$$

Since equation (5) is the exponential function, it is possible to change into the natural logarithm function.

$\ln \left(\frac{P_{i}}{1-P_{i}}\right)=\ln \left(\mathrm{e}^{\left(\beta_{0}+\sum \beta \mathrm{XXi}\right)}\right)=Z_{i}=\beta_{0}+\beta_{1} X_{1}+\beta_{2} X_{2}+\cdots+\beta_{m}------(6)$

$\ln \left(\frac{P_{i}}{1-P_{i}}\right)=\ln \left(\mathrm{e}^{\left(\beta_{0}+\sum \beta \mathrm{iXi}\right)}\right)=Z_{i}=\beta_{0}+\sum_{i=1}^{m} \beta_{i} X_{i}+U_{i}$,

If the disturbance term $U_{i}$ is taking into account the logit model becomes:

$Z_{i}=\beta_{0}+\sum \beta_{i} X_{i}+U_{i}$

Where, $\beta$ s are parameters to be estimated by the model. The intercept $(\beta 0)$ tells how the log odds in favor of food insecurity of the household when all the independent variables are kept constant.

From the above model specification the 15 explanatory variables incorporated in this study will be written in the logit model as the following:-

$\mathrm{P}_{\mathrm{i}}=\mathrm{F}\left(\mathrm{Z}_{\mathrm{i}}\right)=\mathrm{F}\left(\beta_{0}+\sum \beta 16 \mathrm{X} 16\right)=\frac{1}{\left.1+\mathrm{e}^{-\left(\beta_{0}+\sum \beta 16 \mathrm{X} 16\right)}\right)}$

In short by transforming the above nonlinear logit function in to linear logit function to specify mathematical formula of each explanatory variable as follows:-

$Z_{i}=\beta_{0}+\beta_{1} X_{1}+\beta_{2} X_{2}+\beta_{3} X_{3}+\beta_{4} X_{4}+\beta_{5} X_{5}+\beta_{6} X_{6}+\beta_{7} X_{7}+\beta_{8} X_{8}+\beta_{9} X_{9}+\beta_{10} X_{10}+\beta_{11} X_{11}+$

$\beta_{12} X_{12}+\beta_{13} X_{13}+\beta_{14} X_{14}+\beta_{15} X_{15}+\beta_{16} X_{16}+U_{i}$

Where $Z_{i}$ is a function of explanatory variable $X_{i}$ and $\mathrm{i}=1 \ldots . .15$ which may be represented below as:-

$\mathrm{X} 1$ is sex of the household head

$\mathrm{X} 2$ is family size of the household head

$\mathrm{X} 3$ is age of the household head

$\mathrm{X} 4$ is dependency ratio

$\mathrm{X} 5$ is livestock owned by the household head

X6 is nonfarm income of the household head

$\mathrm{X} 7$ is farm income of the household head

$\mathrm{X} 8$ is educational status of the household head

$\mathrm{X} 9$ is farm land size of the household head

$\mathrm{X} 10$ is fertilizer utilization by household head

$\mathrm{X} 11$ is credit use of the household head

$\mathrm{X} 12$ is farming system of the household head

$\mathrm{X} 13$ is distance to market centre by the household head

$\mathrm{X} 14$ is fall armyworm pest

$\mathrm{X} 15$ is food aid to the household head and $\beta_{s}$ are parameters estimated by the model.

\section{Results and Discussion}

In this section the data obtained of the study were presented by using descriptive statistics such as mean, percentage, standard deviation and t-test and chi-squares-test to obtain an overview of the respondents' socioeconomic and demographic characteristics of the households with respective to food insecurity .

In this study, the descriptive analysis was addressed through description of characteristics of the sample households in terms of the major variables which include demographic characteristics (age of household heads, sex of household heads, family size, educational level of household heads and dependency ratio), institutional factors (credit access) and economic factors (livestock ownership, non-farm and farm income and farm size) were expected to affect household food insecurity status. 
Table: $\mathbf{2}$ The descriptive statistics output for continuous variables

\begin{tabular}{|c|c|c|c|c|}
\hline \multirow[b]{3}{*}{ Food security status } & \multicolumn{2}{|l|}{ Food secure } & Food insecure & \multirow[t]{3}{*}{ t-values } \\
\hline & $(n=67)$ & & $(n=312)$ & \\
\hline & Mean SD & & $\mathrm{Me}$ & \\
\hline Age (years) & 38.36232 & 6.333 & $36.368 \quad 7.999$ & $1.9285 * *$ \\
\hline Family size & 6.072464 & 3.758 & $9.073 \quad 2.782$ & $10.928 * * *$ \\
\hline Dependency ratio & 1.3772460 .966 & & 1.7721 .742 & -1.8146 \\
\hline land size & 0.8782609 & 0.643 & 0.742 .613 & $1.6538 * *$ \\
\hline Livestock (TLU) & 32.6811625 .574 & & $13.382 \quad 15.707$ & $7.9736 * * *$ \\
\hline farm income in ETB & 21696.9 & 19148.25 & 4333.8254505 .197 & $13.8579 *$ \\
\hline non-farm income in ETB & 1110.873197 .93 & & 310.04211087 .981 & $3.4866 * *$ \\
\hline Educational level & 2.463768 & 0.7588635 & 2.473684 .734 & -0.100 \\
\hline
\end{tabular}

$* * *, * * \& *$ Significant at $1 \%, 5 \%$ and

$10 \%$ probability levels.

Own survey result (2019).

\subsection{Socio-economic and demographic characteristics of households}

From the table above 2 descriptive statistics output for continuous explanatory variables are expected to affect the household's food insecurity status were explained as follows.

The mean age of the households for food secured and in secured households was 38 and 36 years respectively and standard deviation varies from 6.333 and 7.999 respectively.

The average family sizes of the food secure and insecure households were 6 and 9 unit respectively and standard deviation in the food secure and food insecure households were found to be 3.75 and2.7853respectively.

It was found as significant at the $1 \%$ probability level of $t$ - value of 10.928 . That means the number of family size increases per house hold the probability of food insecurity increases.

The educational level of the sampled household heads was categorized under intervals like illiterate, primary, secondary and college and above and it was insignificantly affect the food insecurity.

The dependency ratio is the ratio of household members whose age below 15 and above 64 years of age to the number of persons in the age group $16-64$ years (active labor force). The mean dependency ratio of food secure households was 1.377 and that of food insecure households was 1.773 respectively. This shows that almost more of the household members in the food insecure household were dependents. The standard deviation for the food secure and food insecure households were 0.96 and 1.774 respectively.

The mean livestock number of food secure and insecure households had 32 and 13 respectively and standard deviation for the food secure and food insecure households were 25 and 15 respectively This indicates food insecure households had less livestock number than food secured household in the study area. There is significant variation of livestock ownership between food secure and food insecure household by per household and statistically significant at $1 \%$ level of significance.

The households' income generation is very important indicator for assurance of food security. From above table 2, the average food secured household got 21,696 ETB farm income by planting and sowing different crops and food insecure household got income of 4,333ETB from the farm income and statistically significant at less than at $1 \%$ probability level. There is the significant farm income difference between food secured household and food insecure households by 17,363 ETB. From the descriptive statistics result above, nearly large number of the sampled households were pastoralist and they were mobile that cannot work in sedentary agricultural practices due lack of good awareness regarding future food security problems. Food secured household in the study area got mean of 1,110 ETB from the non-farm income and food insecure households got 340 ETB from the nonfarm incomes and statistically significant at $5 \%$ level of significance by $t$-test. The standard deviation for the food secure and food insecure households were 3197 and 1087 respectively.

According to result of table 2 above, he mean household land size for food secure and insecure households was about 0.88 and 0.74 hectares respectively and had standard deviation of food secure and insecure households 0.64 and 0.61 respectively. The households of food secure households were possessed less than one hectare implies that the area had a related problems regarding land scarcity. On the other hand, food insecure households also possessed less than half of the hectare and the result showed that almost all food insecure households owned less than one hectare of cultivating land and the result of the t-test showed that it had significance level at below $5 \%$ probability level.

\subsection{Household food insecurity status of sampled households}

Based on the recommended daily food intake of 2,200 kilo calorie, it was observed that $80.5 \%$ of the sampled households of the Woreda were food secured while 19.5\% were found to be food insecure households from the survey result. 
Table 4: Calorie intake of sample households by food insecurity status

\begin{tabular}{lcccl}
\hline Calorie Consumed per AE in (kcals) & Food secure $(\mathrm{n}=67)$ & Food insecure & $(\mathrm{n}=312)$ & Total $(\mathrm{n}=379)$ \\
\hline Minimum & 1200 & 444 & 444 \\
Maximum & 2665 & 2090 & 2665 \\
Mean & 2091.15 & 1356.03 & 1563.46 \\
Standard Deviation (SD) & 308 & 403 & 1368.05 \\
\hline
\end{tabular}

$\mathrm{t}$ - value $=14.160 \mathrm{p}$-value $=0.0000 * * *$

$* * *, * * \& *$ Significant at $1 \%, 5 \%$ and $10 \%$

probability levels. Source: Own

survey result (2019).

The result revealed that from the total sample households $19.5 \%$ and $80.5 \%$ of households were found food secure and food insecure, respectively. The mean calorie available for food secure and insecure households was 2,091.15 and 1,356.9 Kcal/AE/day, respectively. The maximum and minimum energy intake for food secures and insecure households were $2,665 \mathrm{Kcal}$ and $444 \mathrm{Kcal}$, respectively. The survey results showed that the study area could be regarded as food secure given the fact only few households were able to meet the recommended calorie intake of 2,200 Kcal per person per a day and the standard deviation for food secure and food insecure households were found to be $308 \mathrm{kcals}$ and $403 \mathrm{kcals}$ respectively. The t- value (14.160) confirmed that there is significant mean difference between food insecure and secure households (Table 4). The result got this study agrees with the result of (Tolosa, D. and Ayele.B, 1996). Which say calorie take daily by individuals is affect food insecurity status of the households.

\subsection{Econometric analysis}

Before entering the variables in to the model, the multi-co linearity problems were checked in terms of variance inflation factor (VIF) for continuous and contingency coefficients for dummy and discrete variables respectively. As a rule of the thumb, when the variables having VIF values less than the cut off value (10) are believed to have no multi-co linearity problems and those with VIF of above 10 are assumed to have a multi-co linearity problem. Therefore, since, in this study, the computational results of the VIF for continuous variables confirmed the nonexistence of association between the explanatory variables and were included in the model.

In addition to this, the threshold for contingency coefficients for dummy and discrete variables is 0.75 . The values below 0.75 indicate the existence of weak association and above 0.75 indicates strong association of variables. However, the results obtained in this study regarding dummy and discrete variables were less than 0.75 . Therefore, this indicated that there was no any multi-co linearity between dummy explanatory variables.

Moreover, the goodness of model fit was measured in terms of Pseudo R2 which works on the principle that if the predicted probability of the event is greater than 0.50 , the event will occur, otherwise the event will not occur. The model result show the correctly predicted percent of sample household is $69.2 \%$ which is greater than 0.50 .

\subsection{Output of the binary logistic regression model}

Out of 15 independent variables which had been assumed to be significantly related with the status of food insecurity status of the households, the estimation revealed from binary logistic regression that eight variables were found statistically significant (Table5). According from the STATA.V10 result in table 5 these variables were family size dependency ratio, livestock number, farm size, farm income, non-farm income, distance from the market and household production system. 
Table:5 .Determinants of household food insecurity

\begin{tabular}{|c|c|c|c|c|c|}
\hline Food insecurity status & Coef. & Std. & $\mathrm{z}$ & $\mathrm{P}>\mathrm{z}$ & odds ratio \\
\hline $\operatorname{sex}$ & -0.65684 & 1.188693 & -0.55 & 0.581 & 0.5184895 \\
\hline age & 0.065268 & 0.0441125 & 1.48 & 0.139 & 1.067445 \\
\hline Familysize & -0.30431 & 0.1204211 & -2.53 & 0.012 & 0.7376302 \\
\hline educational level & 0.330352 & 0.5112353 & 0.65 & 0.518 & 1.391458 \\
\hline dependency ratio & 0.777563 & 0.3573822 & 2.18 & 0.030 & 2.176162 \\
\hline Farm size & 1.39487 & 0.5673567 & 2.46 & 0.014 & 4.034449 \\
\hline Livestock number & -0.04587 & 0.0191615 & -2.39 & 0.017 & 0.9917213 \\
\hline Farmincome & -0.00049 & 0.0000736 & -6.71 & 0.000 & 0.9996503 \\
\hline nonfarm income & -0.00045 & 0.0001854 & -2.43 & 0.015 & 0.9999138 \\
\hline distance from market & -4.17728 & 1.393153 & -3.00 & 0.003 & 0.2353343 \\
\hline access to credit & 0.004572 & 0.6247356 & 0.01 & 0.994 & 3.417917 \\
\hline Fertilizer utilization & -0.37357 & 0.8476676 & -0.44 & 0.659 & 3.624922 \\
\hline $\begin{array}{l}\text { Food aid } \\
\text { household production }\end{array}$ & 0.993144 & 1.222308 & 0.81 & 0.416 & 29.63109 \\
\hline system & -5.06051 & 1.418022 & -3.57 & 0.000 & 0.1021582 \\
\hline Response to fally warm & -0.33494 & 1.349583 & -0.25 & 0.804 & 10.07633 \\
\hline \multirow{4}{*}{ Binary logistic regression } & $\begin{array}{l}\text { Number } \\
\text { obs }\end{array}$ & $=$ & & 379 & \\
\hline & LR chi2(15) & & $=$ & 241.02 & \\
\hline & Prob> chi2 & & $=$ & 0.0000 & \\
\hline & Pseudo R2 & & $=$ & 0.6918 & \\
\hline
\end{tabular}

$* * *, * * \& *$ Significant at $1 \%, 5 \%$ and $10 \%$ probability levels. Source: Own survey result (2019).

The variables that affect the food insecurity status significantly were family size, dependency ratio, farm size, farm income, non farm income, livestock number, distance from the market and household production system and explained as follows:

Family size: Household size in adult equivalent was significant at less than $1 \%$ probability level in explaining the household food insecurity status. It showed a negative relationship with food security status. This reveals that the negative affect of the increased number of household members in AE on food in security status of the household. Therefore, if other factors are constant, an increase of a single adult equivalent reduces the households' likelihood of being food secure by a factor of 0.73 . This indicates existence higher demand for food as the family member increases. This study result was found consistent with (Haile,KandAlemu ,Z,G, 2005).

Household dependency ratio: It was found to be significant at less than $1 \%$ probability level and had a positive relation with food insecurity status. This showed that in a household where adults or productive age groups (household members aged under the age range of 15 up to 65 rears) are higher than the non-productive age groups, the probability of the household to be food insecure would be high. Therefore, an increase in a unit dependency ratio will increases the households' probability of being food insecure by the factor of 2.17 , if other factors remain the equal. This result was also in line with (Clover J., 2003).

Farm land size is continuous explanatory variable and an important determinant of house hold food insecurity. Farm size is the total area of land cultivated to food and cash crop by households, measured in hectares. Positive relationship has been established between farm size and improvement in households' income and food security it is, therefore, expected of a household with a larger farm size to be more food secures than a household with a smaller farm size and statistically significant at 5\% probability level of significance. As one hectare unit increase in farm size per house hold, the level of food security decreased by 4.03 unit. This study output is agrees with (Getinet KA,2010)

Livestock number: Livestock holding (in TLU) is significantly related at less than $1 \%$ probability level and the odds ratio in favor of being food secure increase by a factor of 0.999 when other factors remain constant. The negative relationship implies that households who possess large herd size had lower probabilities of being food insecure since they can earn more income from livestock production and get opportunity to consume animal products. This in turn enables them to purchase food when they are in short of their stock, and invest in purchase of farm inputs that increase food production, and thus better positioned in ensuring food security at their house hold level. When one unit increases in livestock per house hold, the level of food insecurity decreased by factor of 
lunit and statistically significant at $5 \%$ probability level of significance. The study found is inconsistent with (Shiferaw, F, Kilmer,R.,andGladwin,C,2003). They got the status of food insecurity independent in the number of livestock in house hold level.

Farm income: This source of income is collected from sale of crop produce, sale of livestock and livestock product and hiring of agricultural land. It is negatively related with food insecurity. The more house hold head engage in gainful employment, the higher he/she earns income and the less the chances of being food insecure. An increase one unit of farm income per house hold the probability of food insecure decreased by 0.99 unit and statistically significant at $1 \%$ probability level of significance. The result found here is similar with (Bedeke, S, 2012).

Non-Farm income: This source of income is collected from exchange of different business activities to improve livelihood of for their life by creating entrepreneurship in various business in formal and informal marketing by buying and selling different goods and services. It is negatively related with food insecurity status. The more household head engage in off farm activities, the higher he/she earns income and the less the chances of being food insecure. An increase one unit of farm income per house hold the probability of food insecure decreased by 0.99 unit and it was statistically significant at 5\% probability level of significance.

Distance from the market: Access to market is important to improve house hold food insecurity status. When house hold near to given market they easily buy and sell different goods and services and assure the food security easily. It is negatively related with food insecurity status. That means, when one access to market increases one unit, the level of food insecurity decreased by factor of 0.23 unit odds ratio. It was statistically significant at $5 \%$ probability level of significance.

Production system of household: The way of production system affects the nature of food insecurity of households. It was negatively related with household food insecurity status.

If the houses hold use best production system the level of food security assured easily.

House hold use of technology increases by one unit, the level of food insecurity decreased by factor of 0.10 unit odds ratio. I also explained as pastoral house hold production system is more exposes to food insecurity problems than non-pastoral house hold and it was statistically significant at $1 \%$ probability level of significance. The result found here is different from that found (Negatu, W. 2004 not matter that being pastoral or not matter for assurance food security.

\section{CONCLUSIONS AND RECOMMENDATIONS \\ 5.1 CONCLUSIONS}

The variables that affect the food insecurity status significantly were family size, dependency ratio, farm size, farm income, nonfarm income, livestock number, distance from the market and household production system and the total 354 sampled households, the number of male -headed households and female-headed households are found to be 324 and 30 in number and covers $91.52 \%$ and $8.47 \%$ respectively.

Household size in adult equivalent was significant at less than $1 \%$ probability level in explaining the household food insecurity status. It showed a negative relationship with food security status. This reveals that the negative affect of the increased number of household members in AE on food in security status of the household and the result revealed that from the total sample households $17.6 \%$ and $82.4 \%$ of households were found food secure and food insecure, respectively and showed that in a household where adults or productive age groups (household members aged under the age range of 15 up to 65 rears) are higher than the non-productive age groups, the probability of the household to be food insecure would be high and the way of production system affects the nature of food insecurity of households. It was negatively related with household food insecurity status.

Livestock holding (in TLU) is significantly related at less than $1 \%$ probability level and the odds ratio in favor of being food secure increase by a factor of 0.999 when other factors remain constant. The negative relationship implies that households who possess large herd size had lower probabilities of being food insecure since they can earn more income from livestock production and get opportunity to consume animal products.

The farm of income is collected from sale of crop produce, sale of livestock and livestock product and hiring of agricultural land and it was negatively related with food insecurity. The more household head engage in off farm activities, the higher he /she earns income and the less the chances of being food insecure.

\subsection{RECOMMENDATIONS}

The policy implications of the study are summarized as follows:

Food and nutrition security interventions should integrate family planning, education and awareness raising programs in order to reduce the increasing population pressure on the available scarce resource.

The farm size of the house hold level is too low improve livelihoods of rural farmers in the area For house hold food security improvement there should be on improving the quality of the land through improved soil and water conservation management and strengthening farmers' cooperative unions, implementing good governance and capacity building program interventions may help to have strong land administration that eventually lead to 
building farmers' confidence.

Livestock was found as an important source of wealth that could contribute to food security in the study area.

Hence, the output of the livestock sector should be strengthened through the provision or supply of better veterinary services.

There should be establishment of local market institution to sell their farm inputs to generate daily income levels.

According to from descriptive result most of households food insecure were dependent age groups households, to minimize this problem there should be teaching and training adult and young age groups to escape from the food insecurity problems.

Farmers in the study area should practice both off farm and farm activities to escape from the critical food insecurity challenges to promote the level of incomes.

\section{REFERENCES}

AbduselamAbdulahi Mohammed (2017). Food security situation in Ethiopia: A Review study.International journal of health economics and policy.2 (3), pp. 86-96. Doi: 10.11648/j. hep. 20170203.11

Andy Field (2009). Discovering Statistics Using SPSS. (and Sex and drugs and rock 'n' roll). (3rd edition). 2455 Teller Road. Thousand Oaks, California 91320.

Anna Rabin, 2011. Population Growth and Food Security in the Horn of Africa: Changing demographics in the Horn are affecting food security. Pretoria.

Anderson, Stephen and Elisabeth Farmer.USAID Office of Food for Peace Food Security Country Framework for Ethiopia FY 2016 - FY 2020. Washington, D.C.: Food Economy Group, 2015

AregaBazezewBerlie. (2013). Determinants of Rural Household Food Security in Drought Prone areas of Ethiopia: The Case of Lay Gaint District, Amhara Region. A PhD. Dissertation.Presented to University of South Africa. pp. 201

Gujarati Damodar N. (1988). Basic Econometrics (2nded.). New York: McGraw-Hill.

Gujarati Damodar N. (1995). Basics of Econometrics ( ${ }^{\text {rd }}$ ed.). New York: McGraw-Hill.

Gujarati Damodar N. (2004). Basic Econometrics (4thed.). New York: McGraw-Hill.

Gulled Abdullahi (2006).Food Insecurity and Coping Strategies of Agro-Pastoral Households in AwbareWoreda, Somali Region Ethiopia. An M.sc Thesis Presented to the School of Graduate Studies of Haramaya University.

Haile, K. Alemu, Z. G. Kudhlande (2005): Causes of Household Food Insecurity in

Koredegaga Peasant Association, Oromia Zone, Ethiopia.Working Paper.University of the Free State, South Africa.

Jemal A. Kyung-Ryung K. (2014). Determinants of Household Food Security in Rural Ethiopia.An Empirical Analysis.Journal of Rural Development. 37(2)-pp. 129-157

John H. Aldrich and Forrest D. Nelson (1984)."Linear Probability, logit and probit models." Sage University paper Series on Qualitative Applications in the Social Sciences. Beverly

MOFED. (2008). Ethiopia: Sustainable Development and Poverty Reduction Program. Pp.34, 71, and 76.Federal Democratic Republic of Ethiopia (FDRE) Ministry of Finance and Economic Development. Addis Ababa, Ethiopia.

Ethiopia.An M.Sc. Thesis Presented to School of Graduate Studies. Haramaya University

Mohammed Abdulahi Ibrahim (2016). Food Insecurity and Coping Strategies of Agro Pastoral Households in AwbarWoreda Ethiopian Somali Regional State.An M.Sc. Thesis Presented to School of Graduate Studies, IndraGandhi National Open University. Addis Ababa, Ethiopia

MalleWoreda Office of Livestock and Fishery Resources Development (MWOLFRD, 2016). Disaster report of the year 2015 and 2016 of the MalleWoreda

MalleWoreda Office of Agriculture and Natural Resources Development (MWOANRD, 2015). Annual Summary report of all the year round activities

MalleWoreda Office of Finance and Economic Development (MWOFED, 2016).Basic Annual data of the overall Sectors of the Woreda.

Pinstrup Andersen p. (2009). Food Security: Definition and Measurement of Food Security 1(1)

World Bank, (2012). Pastoral area development in Ethiopia. Issue paper and project proposal. The WB, 1818 H Street, N.W. Washington, D.C., USA.

ZegeyeTirfe (2009). Farm Household Food Insecurity, Determinants, and Coping Strategies: The Case of FadisDistrict, Eastern Oromiya. A M.Sc. Thesis Presented to School of Graduate Studies of Haramaya University, pp. 28

ZerihunNigussie, 2012. Levels of household food insecurity in rural areas of Guraghe zone, Southern Ethiopia Wudpecker Journal of Agricultural Research ISSN 2315-7259 Vol. 2(1), pp. 008 - 014, January 20 